\title{
Requirement of inner cell mass for efficient chorionic gonadotrophin secretion by blastocysts of common marmosets (Callithrix jacchus)
}

\author{
P. M. Summers*, C. T. Taylor and M. W. Miller \\ MRC/AFRC Comparative Physiology Research Group, Institute of Zoology, Zoological Society of \\ London, Regent's Park, London NWI 4RY, UK
}

\begin{abstract}
The role of the inner cell mass in the induction of chorionic gonadotrophin synthesis and secretion by the trophoblast of the peri-implantation primate blastocyst was studied in common marmoset monkeys. An in vitro system for the culture of blastocysts commencing with blastocysts collected 8 days after conception was developed. Chorionic gonadotrophin measured in the spent culture fluid was first detected in most blastocysts after 3 or 4 days (day 11 or 12) of culture at a time equivalent to implantation in vitro. Initial secretion of chorionic gonadotrophin coincided with development of parietal endoderm and histological appearance of syncytiotrophoblast in the polar trophoblast. Little chorionic gonadotrophin was secreted by blastocysts with a poorly developed, or absent, inner cell mass. Mural trophoblast removed from blastocysts after 2 days of culture (day 10) grew in vitro as a unilaminar vesicle but failed to secrete significant amounts of chorionic gonadotrophin. However, mural trophoblast from older blastocysts (days 13 and 14) after chorionic gonadotrophin secretion had commenced continued to secrete chorionic gonadotrophin, with trophoblast from day 14 blastocysts secreting significantly more than that from day 13. It was concluded from these studies that while mural trophoblast from marmoset blastocysts will proliferate in vitro in the absence of an inner cell mass, efficient induction of chorionic gonadotrophin secretion requires the presence of the inner cell mass or its derivatives. Once chorionic gonadotrophin secretion has commenced, secretion will continue in the absence of the inner cell mass.
\end{abstract}

\section{Introduction}

The establishment of mammalian pregnancy depends on the secretion of specific proteins by the conceptus (Roberts et al., 1990). Some of these proteins act directly or indirectly on the corpus luteum to maintain the secretion of progesterone, which in turn ensures an appropriate uterine milieu for the continued survival of the conceptus. This physiological interaction between the conceptus and maternal tissues is referred to as the maternal recognition of pregnancy (Short, 1969). In primates, the product synthesized and secreted by the trophoblast of the implanting blastocyst that rescues the corpus luteum is the glycoprotein, chorionic gonadotrophin (CG) (Heap et al., 1979).

Human fertility is widely recognized as being low (Biggers, 1981) and studies have shown that considerable embryonic loss occurs during the 3 weeks following conception (Chartier et al., 1979; Miller et al., 1980; Whittaker et al., 1983). Irregular and significantly slower doubling time of peripheral blood concentrations of chorionic gonadotrophin have been associated with this embryonic loss (Edmonds et al., 1982; Lenton et al., 1982; Lenton and Woodward, 1988), which implies that inadequate chorionic gonadotrophin secretion may be a factor contributing to the failure of pregnancy.

*Present address: Graduate School of Tropical Veterinary Science and Agriculture, James Cook University, Townsville 4811 Australia.

Received 15 January 1992.
Little is known about the cellular and molecular mechanisms that lead to the initiation of chorionic gonadotrophin synthesis and secretion by the trophoblast of the primate blastocyst despite the considerable progress made in the definition of human chorionic gonadotrophin genes (Stewart et al., 1988). In addition to leading to a better understanding of infertility in women, improved knowledge of these cellular and molecular mechanisms could have a practical application in the development of new methods of contragestation.

The purpose of this study was to define the in vitro growth and chorionic gonadotrophin secretion by peri-implantation blastocysts from the common marmoset monkey (Callithrix jacchus) and to examine the role of the inner cell mass in the control of the growth and chorionic gonadotrophin secretion by trophoblast cells.

\section{Materials and Methods}

\section{Animals}

Marmoset monkeys were from a self-sustaining breeding colony maintained at the Institute of Zoology. Embryo donors were housed in family groups with a fertile male and usually two prepubertal juveniles, and their ovarian cycles were controlled by the intramuscular administration of the prostaglandin 
analogue, cloprostenol (Estrumate: Coopers Animal Health Ltd, Crewe) during the mid- to late luteal phase (Summers et al., 1985). Blood samples were taken from the femoral vein 9,11 and 13 days after cloprostenol injection and the day of ovulation (day 0 ) was determined by measuring plasma progesterone concentrations using a radioimmunoassay (Summers et al., 1985).

\section{Blastocyst collection and culture}

Blastocysts were collected surgically from the uterus 8 days after ovulation (Summers et al., 1987a). Individual blastocysts were cultured in $200 \mu \mathrm{l}$ Hams F10 medium in 96-well flatbottom plastic culture trays (Nunc, Hamstrup, Denmark) at $37.5^{\circ} \mathrm{C}$ in a humidified atmosphere of $5 \% \mathrm{CO}_{2}$ and $95 \%$ air. The culture medium was prepared from Hams F10 powder containing glutamine (Flow Laboratories, Irvine) using twice glass distilled water; $1.2 \mathrm{~g}$ sodium bicarbonate $\mathrm{I}^{-1}$ was added and the $\mathrm{pH}$ adjusted to 7.2 . The medium was supplemented with $20 \%$ $(\mathrm{v} / \mathrm{v})$ heat inactivated fetal calf serum (Flow Labs), penicillin $\mathrm{G}$ $(8 \mathrm{mg}$ in $100 \mathrm{ml})$ and streptomycin $(5 \mathrm{mg}$ in $100 \mathrm{ml}$ ) (Sigma, Poole).

Blastocysts were examined each day under phase contrast microscopy, their stage of development and diameter (including zona pellucida) recorded and they were then transferred into a fresh culture well. The extent of parietal endoderm development was estimated by rotating the blastocyst in the culture medium while they were examined microscopically. When blastocysts formed a firm trophoblast attachment and outgrowth on the bottom of the culture well, the medium was removed carefully and replaced with fresh medium without disturbing the blastocyst. Spent culture medium and that of the control wells was stored at $-20^{\circ} \mathrm{C}$ until assayed for chorionic gonadotrophin concentration.

\section{Removal of mural trophoblast (trophectoderm) cells}

Day 8 blastocysts were subjected to a series of micromanipulative procedures with the aid of a Leitz micromanipulator assembly (Summers et al., 1988) to obtain mural trophoblast. Briefly, a blastocyst was placed in a drop of Dulbecco's phosphatebuffered saline on a glass depression slide, its embryonic pole held by a suction pipette and the zona pellucida opposite the inner cell mass quickly opened with two microhooks. The blastocyst was cultured for 2 days (referred to as day 10 blastocysts) by which time some of the mural trophoblast had herniated through the break made in the zona pellucida. The herniated trophoblast which contained 30-50 cells (Summers et al., 1988) was removed with a scalpel blade by freehand. The mural and polar portions of the blastocyst were cultured separately.

Mural trophoblast was also obtained from blastocysts after they had been cultured for 5 or 6 days; these were referred to as day 13 and day 14 blastocysts, respectively. After careful examination of each blastocyst and noting the position of the inner cell mass and extent of the parietal endoderm, the blastocysts were cut approximately in half by freehand with a scalpel blade avoiding inclusion of parietal endoderm in the portion of the mural trophoblast.

\section{Chorionic gonadotrophin assay}

The biological activity of chorionic gonadotrophin secreted into the culture medium by blastocysts or isolated trophoblast was measured in an in vitro bioassay based on the production of testosterone by dispersed mouse Leydig cells (Van Damme $e t$ al., 1974). Details of the method and its validation for the marmoset have been described previously (Hearn et al., 1988). Assays of samples from each blastocyst included one or two control culture medium samples; concentrations detected in control culture media were subtracted from the test samples. The sensitivity of the assay based on $90 \%$ binding was within the range $2.3-13.6 \mathrm{miu} \mathrm{ml}^{-1}$. The intra- and interassay coefficients of variation of a marmoset plasma pool were $19.9 \%$ and $6.91 \%$, respectively.

\section{Histology}

Blastocysts and trophoblast vesicles were fixed in $2 \%$ glutaraldehyde in $0.05 \mathrm{~mol}$ phosphate buffer $\mathrm{l}^{-1} \mathrm{pH}$ 7.4, embedded in $2 \%$ agar in phosphate-buffered saline (PBS) for ease of handling, dehydrated through graded alcohols and embedded via propylene oxide in epon-araldite. The resin block was oriented so that sections $(1.5-2.0 \mu \mathrm{m})$ could be cut perpendicular to the inner cell mass. Sections were cut until the middle of the inner cell mass was reached and were stained with $1 \%$ toluidine blue.

\section{Immunosurgical isolation of the inner cell mass}

The inner cell mass was isolated from day 10 blastocysts after the herniated trophoblast cells were removed and the blastocysts cultured for $3-5 \mathrm{~h}$ to allow the blastocoel to reform. The zona pellucida was removed by brief exposure (5-10 s) to acidic ( $\mathrm{pH} 2.5)$ Tyrode's solution (Nicholson et al., 1975) and the zona-free blastocyst incubated for $30 \mathrm{~min}$ at $37^{\circ} \mathrm{C}$ in rabbit antimarmoset antisera diluted 1:64 in Ham's F10 plus 20\% fetal calf serum (FCS). Anti-marmoset antisera were produced in a New Zealand white rabbit by an initial i.v. injection of $3.2 \times 10^{7}$ marmoset spleen cells followed by three i.v. injections of $8-16 \times 10^{6}$ peripheral blood leucocytes at 10 day intervals. Blood samples were taken from the rabbit 10 days after the last injection; the serum heat treated at $56^{\circ} \mathrm{C}$ for $30 \mathrm{~min}$ and stored at $-20^{\circ} \mathrm{C}$.

After incubation in anti-marmoset antisera, the blastocyst was washed three times in fresh Ham's F10 plus 20\% FCS and then incubated in fresh guinea-pig serum diluted 1:16 in Ham's F10 plus $20 \% \mathrm{FCS}$ for $30 \mathrm{~min}$ at $37^{\circ} \mathrm{C}$. The lysed trophoblast cells were then removed by gentle pipetting. The isolated inner cell mass was co-cultured with the mural trophoblast cells in $200 \mu \mathrm{l}$ of culture medium.

\section{Statistical analyses}

Log transformation of blastocyst diameters and CG concentrations was carried out to increase the linearity of the data and to reduce the heterogeneity of variance (Helwig and Council, 1979; Sokal and Rohlf, 1981). This is a standard method for improving the quality of the data before carrying out an analysis of variance based on the least squares method (Statistical Analysis System; Helwig and Council, 1979). 


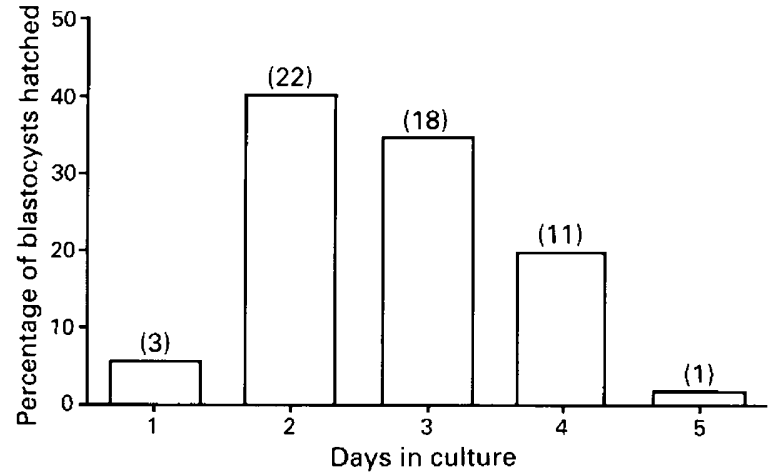

Fig. 1. The percentage of day 8 blastocysts $(n=55)$ that had hatched from the zona pellucida at various days in culture. The number of embryos is shown in parentheses. Blastocysts that had a crack in the zona pellucida on recovery from the uterus were not included in these data.

Separate two-way analyses of variance for repeated measures were carried out on the blastocyst and trophoblast vesicle diameters and CG values. Owing to a significant interaction between blastocyst and vesicle groups and time, one-way analyses of variance for repeated measures were performed separately on each blastocyst and vesicle group and comparisons of individual transformed means were made post hoc using Duncan's multiple range test (Helwig and Council, 1979).

\section{Results}

\section{In vitro development of blastocysts}

Sixty-eight blastocysts were cultured in vitro, of which three (4.4\%) failed to develop and degenerated within 3 days without hatching from the zona pellucida. Eighteen blastocysts were used to obtain mural trophoblast after 5 (day 13) or 6 (day 14) days in culture and of the remaining 47 blastocysts, 27 were fixed for histological examination after varying periods in culture and the remainder (20) were cultured for 10 days (to day 18). Most blastocysts $(72.7 \%)$ hatched from the zona pellucida after 2 or 3 days in culture (Fig. 1).

Blastocysts increased in diameter as they grew in vitro (Fig. 2). The inner cell mass developed from an initial flattened structure to that of a rounded group of cells projecting into the blastocoel after $4-5$ days in culture. It developed further into a cystic structure with a small presumptive amnion and yolk sac in some blastocysts on day 16. Parietal endoderm was evident on gross examination after 3-4 days and extended into between a third and a half of the circumference of the blastocysts after 6 days in culture. Blastocysts became lightly attached to the bottom of the culture dish after 4-5 days and this attachment became firmer with the development of a trophoblast outgrowth over the following 2-3 days. The trophoblast outgrowth developed further over the next 2-4 days, while the blastocyst began to collapse and degenerate. Further culture after 10 days (day 18) left a residual trophoblast monolayer (Summers et al., 1987b).

In five of the 20 blastocysts grown in vitro, there was minimal or no inner cell mass and parietal endoderm development. Although these blastocysts continued to increase in diameter (Fig. 3), they were found to float near the surface of the culture

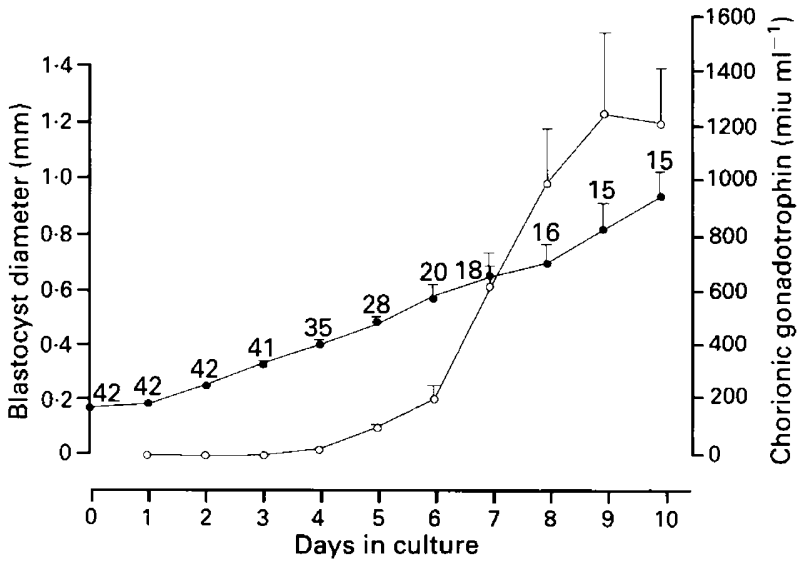

Fig. 2. The growth of blastocysts (O) and chorionic gonadotrophin concentrations $(O)$ in the culture medium (means \pm SEM) of marmoset blastocysts collected 8 days after ovulation and grown in vitro. Fortytwo blastocysts were cultured initially and 15 of these were cultured for 10 days. The remaining blastocysts were fixed for histological examination at various days in culture. One blastocyst underwent extensive degeneration after 8 days in culture and the culture was terminated. The number of blastocysts examined at each day of culture is shown on the graph of blastocyst growth.

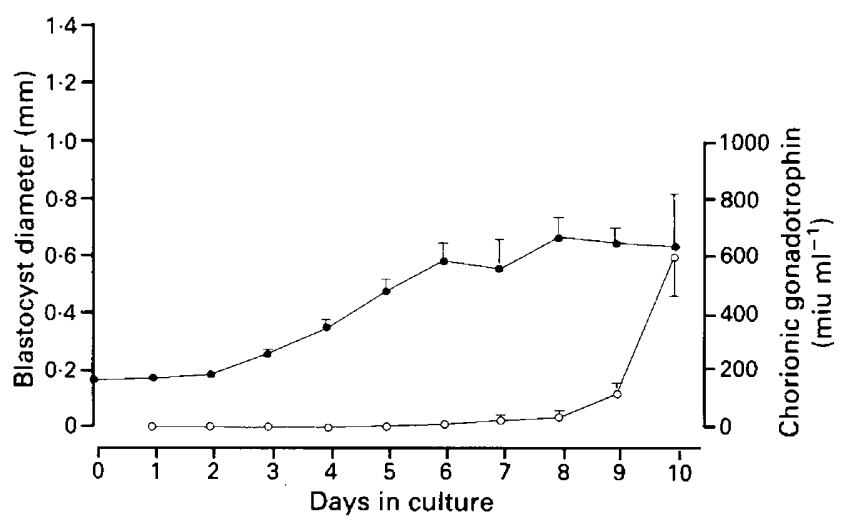

Fig. 3. The growth (O) and chorionic gonadotrophin concentration (O) in the culture medium (means \pm SEM) of five marmoset blastocysts in which minimal or no inner cell mass or parietal endoderm was observed during culture in vitro.

fluid and did not attach to the bottom of the culture dish until after $8-10$ days in culture.

\section{Histological examination of blastocysts grown in vitro}

Parietal endoderm cells were first detected in day 11 blastocysts as a layer of 1-3 elongated cells growing away from the inner cell mass onto the inner surface of the trophoblast. In these day 11 blastocysts, the trophoblast overlaid by the inner cell mass and parietal endoderm cells had differentiated from elongated to cuboidal-type cells. On days 12 and 13 , syncytiotrophoblast cells had begun to appear adjacent to the inner cell mass (Fig. 4b). In day 14 and 15 blastocysts, larger foci of syncytiotrophoblast cells were present adjacent to the inner cell mass 
(a)

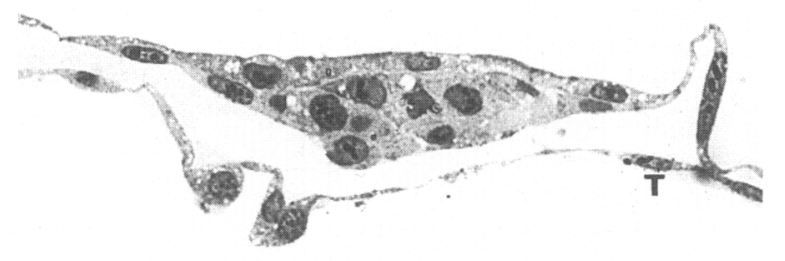

(c)

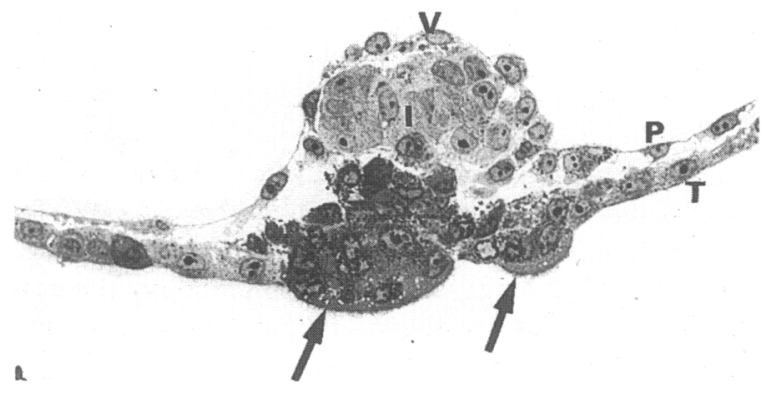

(e) (b)

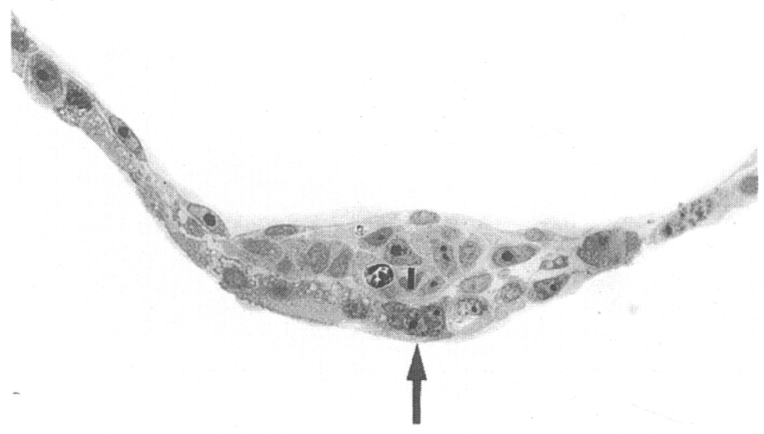

(d)

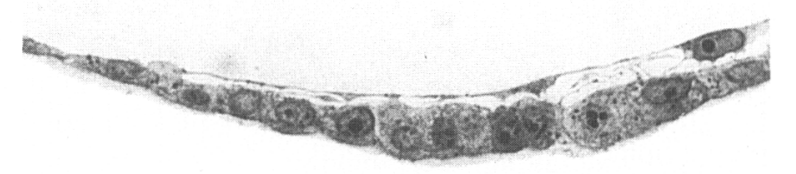

(f)
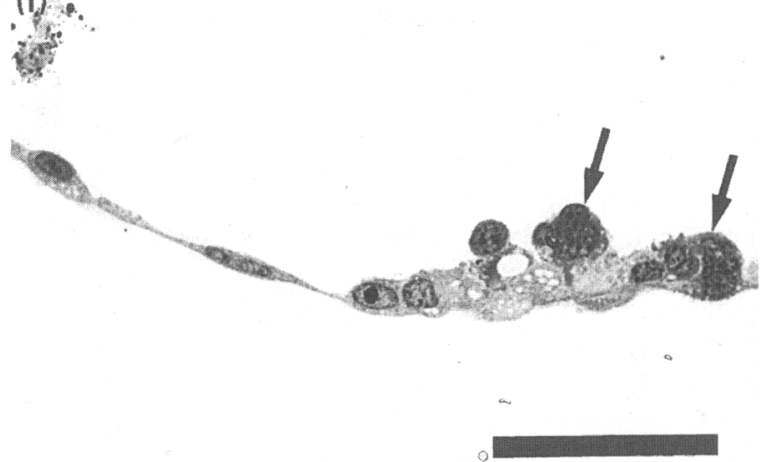

Fig. 4. Photomicrographs of histological sections of marmoset blastocysts and trophoblast vesicles grown in vitro. (a) Day 10 blastocyst; (b) day 12 blastocyst that was secreting chorionic gonadotrophin - note the syncytiotrophoblast cells (arrow) underneath the inner cell mass; (c) day 14 blastocyst - note the large mass of syncytiotrophoblast cells (arrows); (d) day 14 blastocyst, illustrating the transition of trophoblast cells from elongated to cuboidal form at the edge of parietal endoderm growth; (e) section of trophoblast vesicle grown from the mural trophoblast of a day 10 blastocyst; (f) section of a trophoblast vesicle grown from a day 14 blastocyst - note the foci (arrows) of syncytiotrophoblast and cuboidal trophoblast cells interspersed by elongated trophoblast cells. I: inner cell mass; P: parietal endoderm; V: visceral endoderm; T: trophectoderm/trophoblast. Bar $=50 \mu \mathrm{m}$.

(Fig. 4c); syncytiotrophoblast cells could also be found elsewhere in the trophoblast layer in juxtaposition with parietal endoderm cells. The limit of parietal endoderm growth was defined by the transition from cuboidal to elongated cell form (Fig. 4d).

\section{Chorionic gonadotrophin secretion by blastocysts}

Chorionic gonadotrophin was first detected in the culture medium from some blastocysts $(3.1 \%)$ on day 11 but in the majority $(67.4 \%)$ it was detectable on day 12 (Fig. 2). In the remainder of the blastocysts, chorionic gonadotrophin was detected on day 13. Thereafter, there was a sharp rise in the concentration of chorionic gonadotrophin in the spent culture fluid. Blastocysts without an inner cell mass produced minimal amounts of chorionic gonadotrophin (Fig. 3).

\section{Growth and chorionic gonadotrophin secretion by isolated trophoblast}

Mural trophoblast removed from day 10 blastocysts grew in vitro as a unilaminar vesicle but secreted only a small amount of 

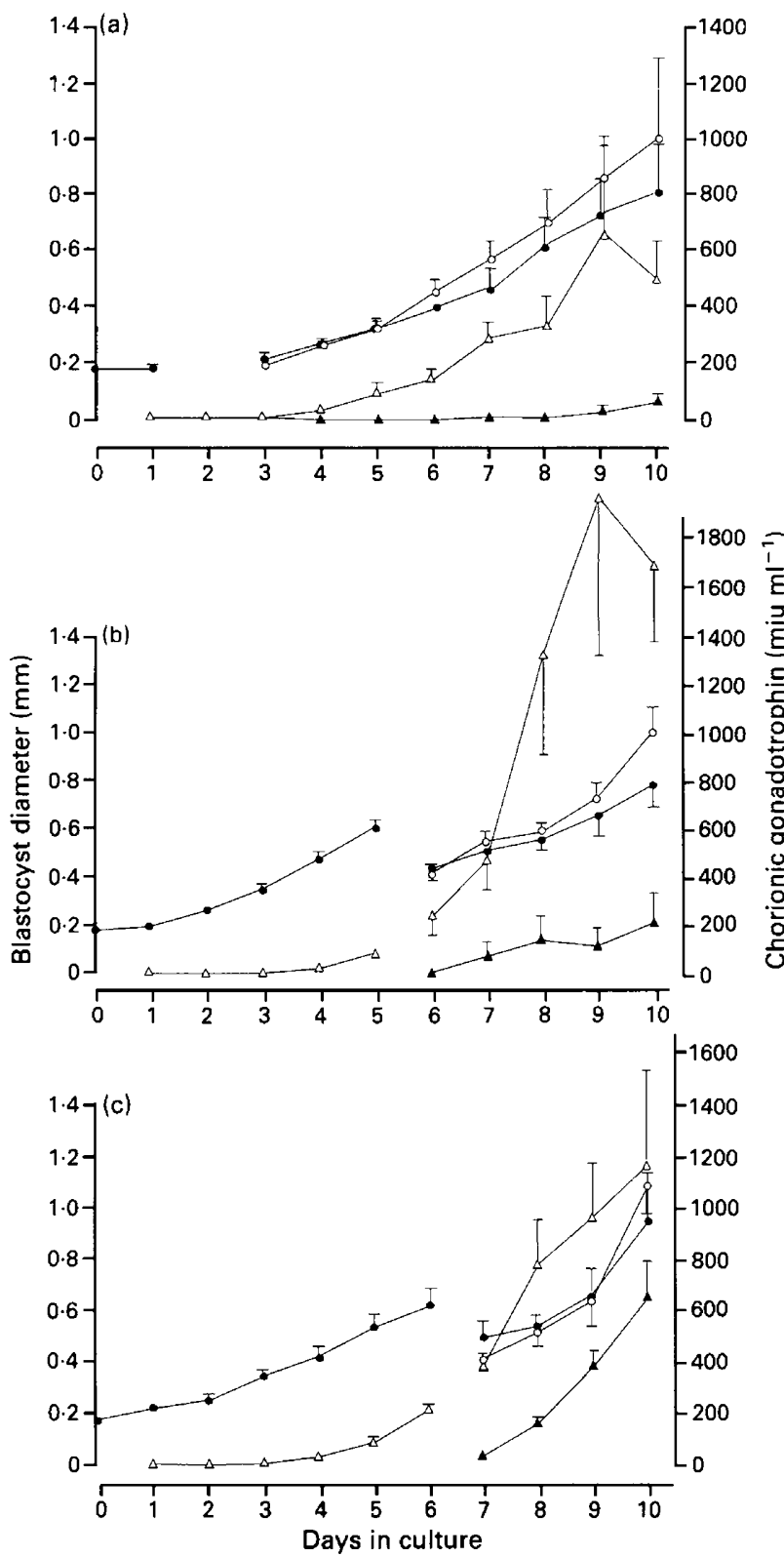

Fig. 5. The growth of residual blastocysts $(O)$ and trophoblast vesicles (O) and chorionic gonadotrophin secretion by residual blastocysts $(\Delta)$ and trophoblast vesicles $(\boldsymbol{\Delta})$ after the removal of mural trophoblast from (a) day 10 blastocysts, $n=12$, (b) day 13 blastocysts, $n=9$, (c) day 14 blastocysts, $n=9$. Means \pm SEM.

chorionic gonadotrophin towards the end of the culture period. The residual blastocysts commenced secretion of chorionic gonadotrophin at the same time as intact blastocysts (Figs 2 and $5 a)$, but secreted significantly less chorionic gonadotrophin during the last 3 days of culture $(F(1,24)=14.32, P<0.009$; $F(1,23)=6.55, P<0.02 ; F(1,22)=9.26, P<0.006)$, although the residual blastocysts were not significantly smaller at this stage compared with intact blastocysts. Trophoblast from day 13 and 14 blastocysts also grew as vesicles which were similar in diameter to vesicles from day 10 blastocysts on days $7,8,9$ and 10 of culture. Trophoblast vesicles from day 13 blastocysts produced moderate amounts of chorionic gonadotrophin, whereas vesicles from day 14 blastocysts secreted significantly greater amounts on days 9 and 10 of culture compared with vesicles from day 13 blastocysts (Figs $5 b$ and $5 c ; F(1,12)=11.14$, $P<0.006 ; F(1,10)=5.47, P<0.05)$. Six trophoblast vesicles originating from day 10,13 and 14 blastocysts were examined histologically; all were unilaminar and there was no evidence of parietal endoderm. Vesicles derived from day 10 blastocysts comprised only elongated trophoblast cells (Fig. 4e). The wall of trophoblast vesicles derived from the mural trophoblast of day 14 blastocysts was characterized by foci of syncytiotrophoblast and cuboidal trophoblast cells interspersed by elongated trophoblast cells (Fig. 4f). Foci of cuboidal cells were present in vesicles from day 13 blastocysts but syncytiotrophoblast cells were observed only occasionally.

Trophoblast vesicles $(n=5)$ from day 10 blastocysts that had been co-cultured for 8 days with an immunosurgically isolated inner cell mass also failed to secrete significant quantities of chorionic gonadotrophin. In these experiments, there was morphological evidence of growth of the inner cell mass. Typically, the inner cell mass would develop as a cystic structure and become attached after 3-5 days in culture by a monolayer outgrowth of uniform epithelioid cells. These cells had a large nucleus and prominent peri-nuclear granules and did not resemble trophoblast cells in morphology. The exact nature of these cells was not determined but they were presumed to be derived from parietal endoderm.

\section{Discussion}

These results demonstrate that marmoset preimplantation blastocysts can be readily grown in vitro and that they begin to secrete biologically active chorionic gonadotrophin at a time equivalent to implantation in vivo, which is 11-12 days after ovulation in the marmoset (Moore et al., 1985). Development in vitro to day 13 was comparable to in vivo development, but by day 16 there was retarded development of the inner cell mass in many blastocysts (Moore et al., 1985; Smith et al., 1987). Although chorionic gonadotrophin was detected in vitro on days 11-12, significant systemic concentrations of chorionic gonadotrophin as measured by the Leydig cell bioassay have not been detected until 17 days after ovulation (Hearn et al., 1988). This is somewhat later than in women and old world primates in which chorionic gonadotrophin is detected in peripheral blood on days '9-12 of pregnancy (Hodgen, 1979; Lenton et al., 1982) and can be attributed to the slower development of preimplantation marmoset embryos (Summers et al., 1987a).

The evidence from this and other studies in vitro in marmosets (Hearn et al., 1988), baboons (Pope et al., 1982) and humans (Fishel et al., 1984; Lopata and Hay, 1989) indicates that the uterine environment is not essential for the initiation of chorionic gonadotrophin synthesis. In addition, attachment to the culture dish was not a prerequisite for the initiation of chorionic gonadotrophin synthesis, as secretion into the culture fluid preceded attachment by 1 or 2 days. This result is consistent with the observations by Lopata and Hay (1989) for human blastocysts, although Pope et al. (1982) reported that baboon blastocysts grown in vitro secreted chorionic gonadotrophin after attachment had occurred. 
The syncytiotrophoblast is believed to be the site for chorionic gonadotrophin synthesis in the human placenta (Midgley and Pierce, 1962; Beck et al, 1969). The detection of chorionic gonadotrophin in the culture fluid from marmoset blastocysts correlated positively with the histological presence of syncytiotrophoblast cells adjacent to the inner cell mass and developing parietal endoderm. Whether syncytiotrophoblast development is a cause or effect of chorionic gonadotrophin secretion is not known, but the efficient initiation of chorionic gonadotrophin secretion does depend on the presence of an inner cell mass, parietal endoderm or both. Blastocysts with a poorly developed or no inner cell mass and trophoblast vesicles derived from blastocysts before chorionic gonadotrophin secretion had commenced produced minimal amounts of chorionic gonadotrophin at a time when control blastocysts were secreting substantial amounts.

Failure of the co-culture of immunosurgically isolated inner cell mass with trophoblast vesicles to trigger chorionic gonadotrophin synthesis suggests that intimate cell contact between the inner cell mass and trophoblast may be necessary to initiate chorionic gonadotrophin synthesis. Alternatively the co-culture system failed because the induction signal from the inner cell mass or from the outgrowth of putative parietal endoderm cells was not produced under these in vitro conditions. Another possibility is that the signal for inducing chorionic gonadotrophin synthesis and secretion has to be applied to the inner surface of trophectoderm cells.

The ability of mural trophoblast from day 14 blastocysts to secrete substantial amounts of chorionic gonadotrophin indicates that at this stage of development many mural trophoblast cells had received a signal to synthesize and secrete chorionic gonadotrophin. It follows that fewer cells of day 13 blastocysts had received this signal when mural trophoblast cells were removed. It is also of note that more syncytiotrophoblast cells were observed in histological sections of vesicles grown from day 14 than from day 13 mural trophoblast. On the basis of histological and phase contrast examination, mural trophoblast removed from day 14 blastocysts was not lined by parietal endoderm. This evidence argues against the concept that the induction signal arises because of intimate contact between the parietal endoderm cells and trophoblast and suggests that the signal is a product of the inner cell mass or parietal endoderm which diffuses through the blastocoel fluid to the trophoblast cells.

Once marmoset trophoblast has begun to secrete chorionic gonadotrophin, it can continue to do so in the absence of the inner cell mass or its derivatives. This was shown by the continued secretion of chorionic gonadotrophin from mural trophoblast from day 13 or 14 blastocysts and by our previous studies (Summers et al., 1987b), in which long term propagatable cultures of trophoblast derived from intact marmoset blastocysts continued to secrete chorionic gonadotrophin. This feature of primate trophoblast is the likely explanation for the near normal peripheral blood concentrations of chorionic gonadotrophin found in the 'blighted ovum' syndrome in human pregnancies (Hertig, 1975; Edwards, 1985). In this condition, the embryonic disc degenerates after implantation but the trophoblastic tissue continues to survive and secrete chorionic gonadotrophin for several weeks, sometimes up to 10 weeks.
In contrast to the situation in mice (Gardner, 1972) and guinea-pigs (Ilgren, 1980) mural trophoblast from marmoset blastocysts will continue to proliferate in the absence of the inner cell mass. However, the ability to proliferate and form a vesicle depends on the number of cells removed. Groups of less than 20 cells taken from day 9 or 10 blastocysts undergo limited cell replication and quickly develop into a monolayer of syncytial and binucleate cells (Summers et al., 1988). Trophoblast excised from bovine, ovine and porcine blastocysts 12-18 days after conception can also form trophoblast vesicles, although cellular proliferation appears to be limited (Camous et al., 1984; Hickey and Hansel, 1987; Whyte et al., 1987). It is also of note that this tissue is probably not pure trophoblast and is likely to include parietal endoderm (Heyman et al., 1984).

In conclusion, these experiments show that the inner cell mass, its derivatives or both are required for the efficient induction of chorionic gonadotrophin secretion by the trophoblast of peri-implantation blastocysts. However, in vitro growth of trophoblast is not dependent on the inner cell mass nor is it necessary for the continued secretion of chorionic gonadotrophin once secretion has commenced.

We thank T. Noble and staff for the care and maintenance of animals. These studies were supported by programme grants from the Medical Research Council (UK) and the Agricultural and Food Research Council (UK).

\section{References}

Beck JS, Gordon RL, Donald D and Melvin JMO (1969) Immunofluorescent localization of hCG in chorionic villus of man Joumal of Pathology and Bacteriology 97 545-555

Biggers JD (1981) In vitro fertilization and embryo transfer in human beings $N e w$ England Journal of Medicine 304 336-342

Camous S, Heyman Y, Meziou W and Mènézo Y (1984) Cleavage beyond the block stage and survival after transfer of early bovine embryos cultured with trophoblast vesicles Journal of Reproduction and Fertility 72 479-485

Chartier M, Roger M, Barrat J and Michelon B (1979) Measurement of plasma hcG and $\beta$ hcG activities in the late luteal phase: evidence of the occurrence of spontaneous menstrual abortions in infertile women Fertility and Sterility $\mathbf{3 1}$ 134-137

Edmonds DK, Lindsay KS, Miller JF, Williamson I and Wood PJ (1982) Early embryonic mortality in women Fertility and Sterility 38 447-453

Edwards RG (1985) Normal and abnormal implantation in the human uterus. In Implantation of the Human Embryo pp 303-333 Eds RG Edwards, JM Purdy and PC Steptoe. Academic Press, London

Fishel SB, Edwards RG and Evans C (1984) Human chorionic gonadotrophin secreted by preimplantation embryos cultured in vitro Science $223816-818$

Gardner RL (1972) An investigation of inner cell mass and trophoblastic tissue following their isolation from the mouse Journal of Embryology and Experimental Morphology 28 279-312

Heap RB, Flint AP and Gadsby JE (1979) Role of embryonic signals in the establishment of pregnancy British Medical Bulletin 35 129-135

Hearn JP, Hodges JK and Gems S (1988) Early secretion of chorionic gonadotrophin by marmoset embryos in vivo and in vitro Joumal of Endocrinology 119 249-255

Helwig JT and Council KA (1979) SAS Users Guide. SAS Institute Inc., Cary

Hertig AT (1975) Implantation of the human ovum: the histogenesis of some aspects of spontaneous abortion. In Progress in Infertility pp 411-427 Eds SJ Behrman and RW Kistner. Little Brown \& Co., Boston

Heyman Y, Camous S, Fèur J, Meziou W and Martal J (1984) Maintenance of the corpus luteum after uterine transfer of trophoblastic vesicles to cyclic cows and sheep Joumal of Reproduction and Fertility 70 533-540

Hickey GJ and Hansel $W$ (1987) In vitro synthesis of a low molecular weight lipid-soluble luteotrophic factor by conceptuses of cows at day 13-18 of pregnancy Journal of Reproduction and Fertility $\mathbf{8 0} 569-576$ 
Hodgen GD (1979) Patterns of secretion and antigenic similarities among primate chorionic gonadotrophins: significance in fertility research. In Chorionic Gonadotrophin pp 53-64 Ed. SJ Segal. Plenum Press, New York

Ilgren EB (1980) The growth of tissues isolated from the guinea pig embryo in vitro Journal of Embryology and Experimental Morphology 60 405-418

Lenton EA and Woodward AJ (1988) The endocrinology of conception cycles and implantation in women Journal of Reproduction and Fertility Supplement 36 1-15

Lenton EA, Neal LM and Sulaiman R (1982) Plasma concentrations of human chorionic gonadotrophin from the time of implantation until the second week of pregnancy Fertility and Sterility 37 773-778

Lopata A and Hay DL (1989) The surplus human embryo: its potential for growth, blastulation, hatching, and human chorionic gonadotrophin production in culture Fertility and Sterility 51 984-991

Midgley AR and Pierce GB (1962) Immunohistochemical localisation of human chorionic gonadotrophin Joumal of Experimental Medicine 115 289-294

Miller JF, Williamson E, Glue J, Gordon YB, Grudzinskas JG and Sykes A (1980) Fetal loss after implantation Lancet ii 554-556

Moore HDM, Gems S and Hearn JP (1985) Early implantation stages in the marmoset monkey (Callithrix jacchus) American Joumal of Anatomy 172 265-278

Nicholson GL, Yanigamachi R and Yanigamachi H (1975) Ultrastructural localisation of lectin binding sites on the zonae pellucidae and plasma membranes of mammalian eggs Joumal of Cell Biology 66 263-274

Pope VZ, Pope CE and Beck LR (1982) Gonadotrophin production by the baboon embryo in vitro. In In vitro Fertilization and Embryo Transfer pp 129-134 Eds ESE Hafez and J Semm. MTP Press, Lancaster

Roberts RM, Farin CE and Cross JC (1990) Trophoblast proteins and maternal recognition of pregnancy Oxford Reviews of Reproductive Biology 12 147-180

Short RV (1969) Implantation and the maternal recognition of pregnancy. In Foetal Autonomy pp 21-26 Ciba Foundation Symposia No. 23. Churchill, London
Smith CA, Moore HDM and Hearn JP (1987) The uitrastructure of early implantation in the marmoset monkey (Callithrix jacchus) Anatomy and Embryology 175 399-410

Sokal RR and Rohlf FJ (1981) Biometry: The Principles and Practice of Statistics in Biological Research (2nd edn). W.H. Freeman and Company, New York

Stewart JH, Jones DSC, Pascall JC, Poplin RM and Flint APF (1988) The contribution of recombinant DNA techniques to reproductive biology Journal of Reproduction and Fertility 83 1-57

Summers PM, Wennink CJ and Hodges JK (1985) Cloprostenol-induced luteolysis in the marmoset monkey (Callithrix jacchus) Journal of Reproduction and Fertility 73 133-138

Summers PM, Shephard AM, Taylor CT and Hearn JP (1987a) The effects of cryopreservation and transfer on embryonic development in the common marmoset monkey, Callithrix jacchus Journal of Reproduction and Fertility $\mathbf{7 9}$ 241-250

Summers PM, Taylor CT and Hearn JP (1987b) Characteristics of trophoblastic tissue derived from in vitro culture of preimplantation embryos of the common marmoset monkey Placenta 8 411-422

Summers PM, Campbell JM and Miller MW (1988) Normal in vivo development of marmoset monkey embryos after trophectoderm biopsy Human Reproduction 3 389-393

van Damme MP, Roberts DM and Diczfalusy E (1974) An improved in vitro bioassay method for measuring luteinizing hormone (LH) activity using mouse Leydig cell populations Acta Endocrinologica 77 655-671

Whittaker PG, Taylor A and Lind T (1983) Unsuspected pregnancy loss in healthy women Lancet i 1126-1127

Whyte A, Wooding FBP and Saunders PTK (1987) Characteristics of cellular structures derived by tissure culture of pre-implantation blastocysts of the pig Archives d'anatomie microscopique et de morphologie expérimentale 75 91-109 